\title{
CRITICAL REVIEW (CRITICAL INFORMATION MODEL) \\ Paths for a successful career as a researcher
}

\section{Katia Nunes Sá, Abrahão Fontes Baptista**}

* Doutorado em Medicina e Saúde Humana pela Escola Bahiana de Medicina e Saúde Pública. Atualmente é professora adjunta da Escola Bahiana de Medicina e Saúde Pública. E-mail: katia.sa@bahiana.edu.br

** Doutorado em Ciências Morfológicas pela Universidade Federal do Rio de Janeiro e Pós-doutorando na University of Western Sydney. Atualmente é professor adjunto III da Universidade Federal da Bahia. É responsável pelo Laboratório de Eletroestimulação Funcional da UFBA, professor do quadro permanente do Programa de Pós-graduação em Medicina e Saúde da UFBA e professor colaborador dos Programas de Pós-graduação em Medicina e Saúde e Tecnologia e Saúde da EBMSP. E-mail: abrahao.baptista@gmail.com

Work: Alan M Johnson. CHARTING A COURSE FOR A SUCCESSFUL RESEARCH CAREER. Netherlands: Elsevier, 2011, 120 pp.

The author

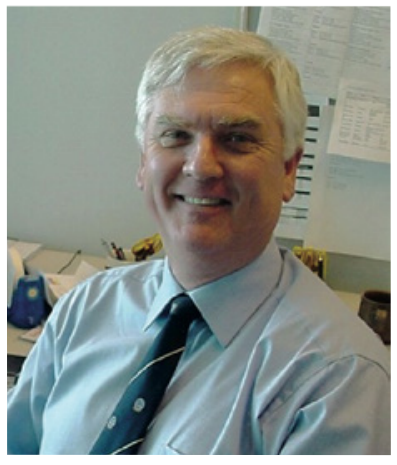

Emeritus Professor Alan Johnson AM, has more than 30 years of experience in research, research management and research training in universities, Australian Government agencies and international research organizations. He obtained his Bachelor's degree in Biomedical Technology Bachelor (South Australian Institute of Technology), and Ph.D. in Parasite Immunology (Flinders University, Australia), and Postdoctoral Research Fellow at the United States Department of Agriculture. During his research career he published over 100 internationally refereed journal articles and received over \$3.5 million in competitive grant funding. 


\section{THE WORK}

With Elsevier support, this work involves the theme of how on the last 10 to 15 years, competition for high profile research positions has become much more challenging and what is necessary to build a successful research career. It is composed of 17 chapters that address career planning, selecting research discipline, supervisor and mentor, collaboration with research teams and between industry and academy, networking, publication's style and format, where to publish, preparing a grant funding application, attending conferences, society membership, selling accomplishments, curriculum and applying for fellowships, jobs or promotion.

\section{CRITICAL ABSTRACT \\ Principles}

The European Union use the Frascati definition of researchers as "Professionals engaged in the conception or creation of new knowledge, products, processes and methods and systems, and in the management of the projects concerned" and research as "creative work undertaken on a systematic basis in order to increase the stock of knowledge, including knowledge of man, culture and society, and the use of this stock of knowledge to devise new applications".(1)

Research can be classified as:

Pure basic research - experimental and theoretical work often called fundamental or "blue sky" research, "know- ledge for knowledge's sake".

Strategic basic research - experimental and theoretical, but often undertaken to acquire new knowledge and lead to useful discoveries or solve practical problems.

Applied research - original work to perhaps determine new ways of achieving specific objectives or developing new techniques.

Independent of research type, The Ph.D. and equivalents degrees are internationally recognized qualifications. Having the ability to plan for a global research environment is an ideal aim for all Early Career Researcher (ECR).

\section{CAREER PLANNING}

In this chapter, the work compares the university professor, with the researcher from a research institute or industry. Each one has different responsibilities and focus. The university is a corporation with mission to develop human skills and resources. The research institute is a corporation where the mission is to develop solutions for society problems. At the industry, the mission is building products and consumer goods for society, and involves a natural look for commercial profit. ${ }^{(2)}$ 
The author suggest that it is very important to have a clear focus in each of those three different areas of research, and to consider and adequate time frame to achieve each strategic goal $(5,10$ and 15 years for each strategic objectives and goals) in career planning.

The principal requirement is to be proactive, optimist and realist. Also, it is very important to know very well the conditions in each regulation and assessment agency to prepare the desirable curriculum vitae. Perhaps, it recommends work/life balance because the ideal is to have a "smarter" not "harder" work.

\section{SELECTING RESEARCH DISCIPLINE, SUPERVISOR AND MENTOR}

In those three chapters, the author recommends the search for niches and opportunities to be an expert and a reference in a specific subject. Perhaps the last major factor of importance in research career is to consider whether you wish to work in large teams or more independently. There are advantages and disadvantages to both approaches. The opportunities and conditions to work are very important, and should be taken into account during career planning.

Each government or industry research team and university research center or institute has a Director or Head. You need to know some characteristic about the structure, behavior and institutional aims, specially about the Director or Head, because it may affect the research career.

The supervisor is naturally the person who opens the doors in research career. It is essential to have affinities and a positive relationship between supervisor and researcher in training. Formal research groups, where members have opportunities to share experiences, help each other resting on the experience of supervisor. They are the most suitable place for the development of researcher's career. ${ }^{(3)}$
A good Mentor who is prepared to give free and open, but critical advice on your research career is invaluable. The best Mentor is someone who may not even be in the same research discipline or even the same department or organization. The most important factor in identifying a Mentor is that he/ she is able to, and will, provide essential critical comments. There should be a mutual respect so that he/she can advise or suggest that you may be wrong or your ideas or focus may be incorrect.

\section{RESEARCH COLLABORATION, FINANCIAL APPROACHES AND NETWORKING}

Research collaboration is an essential part of networking, and is a major component of most research productivity. But, it is essential to decide why to do collaboration and which advantages outweigh the potential disadvantages. The collaboration needs to help both involved parts to be a balanced relationship.

A big problem involved in those questions is a potential interest conflict in publications. The Vancouver Protocols recommend that authorship credit should be based on (1) substantial contributions to conception and design, acquisition of data, or analysis and interpretation of data; (2) drafting the manuscript or revising it critically for important intellectual content; and (3) final approval of the version to be published. (4) There are many recommendations for planning and inclusion of authors in scientific publications. (5) Many research collaborations are extremely productive for all involved, and last for extended periods. Other collaborations may be of a more defined goal, with short time frames, and may involve the donation of laboratory reagents or translation of texts.

The most important for the success of an efficient and productive work of research involves the aggregation of human resources that contribute to the development of projects. This team inserted into an appropriated physical infrastructure, with 
clear goals, and expert researchers are the key of success. Working as a fellowship ERC can improve expert management in different approaches.

\section{ETHICS AND RESEARCH INTEGRITY}

On this topic the work draws attention for a new international effort to enhance the quality and transparence of research, including Big Data, registers and access to complete information involved in a specific research. This is the "right" thing to do for many ethical and social reasons and it makes good sense to plan and carry out your research in this way.

\section{PUBLICATION'S STYLE AND FORMAT, AND WHERE TO PUBLISH, AND GRANT APPLICATION}

Each one has a proper style and format that mirroring a singularity to individual contributions. However, the scientific language asks in each area a specific communication style. The sooner you learn this pattern, the faster you grow as a researcher, since the publications and citations made reflect the ability of the researcher in tracking the relevant literature of the specific research field. ${ }^{(6)}$

Open access journals are the most important setting to publish because there is an international policy for the provision of universal scientific information. (7) But there are other requirements to a relevant research product, as publishing in journals with good impact factor, reliability of societies and institutions involved, agencies of assessment, as the Coordination of Improvement of Higher Education in Brazil. (8) The problem of increasing costs to publish in open access journals is continuously been addressed by funding Agencies by proper grants and funding.

The grant foundation application is not only to get funding for research or for publication, but just expresses the quality of the whole method developed to be evaluated blindly by highly demanding pairs in a very competitive setting. ${ }^{(9)}$

\section{ATTENDING CONFERENCES AND SOCIETY MEMBERSHIP}

In the beginning of a research career everyone needs to do some things that over time will become less important. Attending conferences is one of these. However, if you decide to present a conference you need to plan this as well as possible, because you will be very exposed.

To be a society membership can be important to be knowledge in a specific or general research group. The changes in ordinal meetings are very necessary for the progress of research and finding opportunities for collaborations.

\section{FINAL CONSIDERATIONS}

A career in research is an exciting adventure. You are fortunate to have been able to make the most of the opportunities presented to you and earned a PhD. Hard work and always aiming for high quality outputs will allow you to succeed and indeed flourish in the research environment. A research career is a most worthwhile calling in life as you add your new knowledge to advance humankind. In most cases, the investment we make in our careers as researchers is proportional to the return on opportunities and recognition by the society. ${ }^{(10)}$

Brazil has almost half of the physiotherapist of the total amount in the world. This scenario places Brazilian physiotherapy researchers in a special and very demanding place. The need for profession development associated with high quality research ask for very original ideas and research questions, proactive and skilled teams and adequate facilities. Career planning is outstanding to achieve good results in the future, both for the researcher, and the community. 


\section{REFERENCES}

1. Organisation for Economic Co-operation and Development. Frascati Manual: Proposed Standard Practice for Surveys on Research and Experimental Development. [Paris]: OECD Publishing; 2002.

2. League of European Research Universities. Research universities and research assessment. [Leuven]: LERU; $2 \mathrm{Ol} 2$.

3. Katz JS, Martin BR. What is research collaboration? Res Policy. 1997;26(1):1-18.

4. Vancouver Protocol. Uniform Requirements for Manuscripts Submitted to Biomedical Journals. Recuperado de http://www.research.mq.edu.au/ documents/policies/Vancouver.pdf

5. Petroianu A. Critérios para autoria e avaliação de uma publicação científica - Criteria for authorship and evaluation of a scientific paper. Rev Psiquiatr Clín. 2010;37(1):1-5.
6. Griffies SM, Perrie WA, Hull G. Elements of Styles for Writing Scientific Journal Articles. [S.I.]: Elsevier; 2013.

7. Pinheiro LVR. Do acesso livre à ciência aberta: conceitos e implicações na comunicação científica. RECIIS - Rev. Eletron. de Comun. Inf. Inov. Saúde. 2014; 8(2):153-65.

8. Alvarez AM. Panorama e diagnóstico da oferta e qualidade da Educação Superior no Brasil. Projeto CNE/UNESCO 914BRZ1136.3. 2013.

9. Pequegnat W, Stover E, Boyce CA. How to Write a Successful Research Grant Application: A Guide for Social and Behavior Scientists. [New York]: Springer; 2011.

10. King DA. The scientific impact of nations. Nature. 2004;430:311-316. doi:10.1038/430311a

11. Calvalcante CCL, Rodrigues ARS, Dadalto TV, Silva EB. Evolução científica da fisioterapia em $4 \mathrm{O}$ anos de profissão. Fisioter mov. 2011;24(3):513-522. 